Original Research

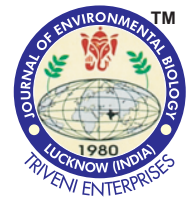

(9) (-)

\title{
Differential response of pearl millet genotypes to high temperature stress at flowering
}

Authors Info

\section{A.K. Jukanti*, V.K. Manga,} R.K. Bhatt and R. Pathak

Division of Plant Improvement, Propagation and Pest Management, ICAR-Central Arid Zone Research Institute, Jodhpur-342 003, India

*Corresponding Author Email : aravindjukanti@gmail.com

Key words

Heat stress,

Pearl millet cultivars,

Stress indices

Publication Info

Paper received : 10.08 .2016

Revised received: 18.11.2016

Re-revised received : 06.12.2016

Accepted : 20.12.2016

\begin{abstract}
Aim : Pearl millet is emerging as an important irrigated summer crop in India and Africa. Flowering during summer coincides with high temperature resulting in reduced grain yield. Due to limited cultivar options for summer, different types of pearl millet genotypes were evaluated to identify sources of high temperature tolerance.

Methodology : Fourteen pearl millet cultivars (4 each of population and hybrids; 3 each of inbred restorers and MS lines) were evaluated under two sowing dates in such a way that the flowering was not/minimally affected by high temperature stress (non-stress - NST) and the flowering largely coincided with high temperature $\left(\geq 42^{\circ} \mathrm{C}\right)$, impacting the seed set and grain yield (stress - ST). The data on different parameters including grain yield was recorded and different stress indices were estimated.
\end{abstract}

Results : The total number of days each genotype flowered was reduced by $\sim 2-3$ days under high temperature stress, probably an inherent avoidance mechanism. Per cent decrease in seed set and grain yield under stress was $2.4-29.9$ and $12.2-40.9$, respectively. High temperature stress $\left(\geq 42^{\circ} \mathrm{C}\right)$ during flowering stage resulted in reduced seed set, tip sterility and reduced panicle exertion. Increased vegetative growth (plant height) coupled with reduction in grain yield were recorded for all the genotypes under heat stress. Under temperature stress, hybrids outperformed the others in terms of seed set and grain yield. Based on heat tolerance/susceptibility indices, seed set and grain yield CZH 233, CZP 9603, CZI 2011/5 and CZMS 21A were the best performing genotypes.

Interpretation : High temperature affects the assimilate production and reproductive growth, thereby significantly reduced the grain yield. The results demonstrated that flowering period is an important heat sensitive stage. Genetic variability exists for flowering stage high temperature tolerance in pearl millet which can be utilized in developing improved cultivars for summer cultivation.
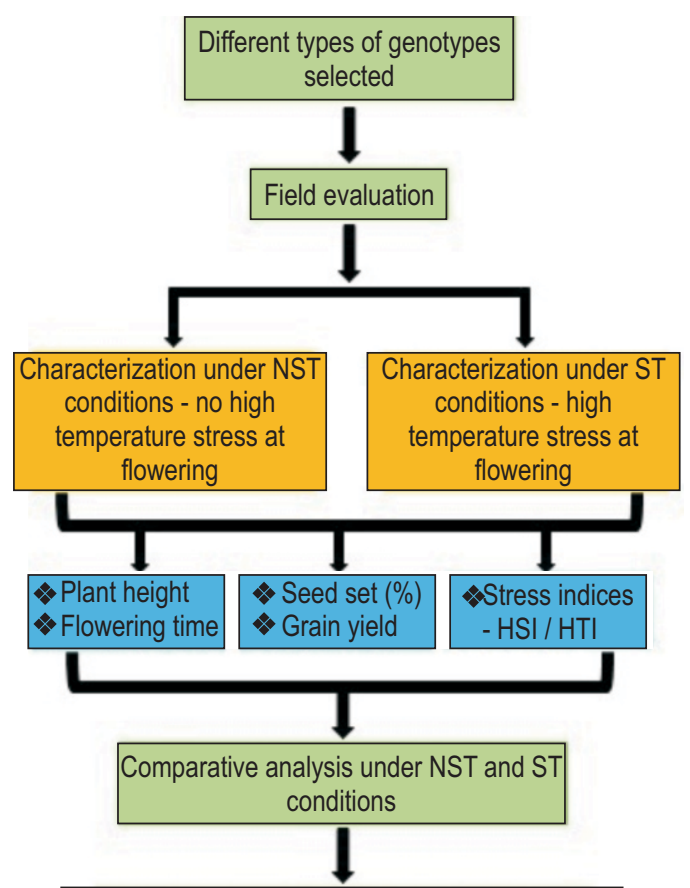

Identification of high temperature tolerant sources 


\section{Introduction}

Pearl millet (Pennisetum glaucum) is an important millet crop cultivated for its grain and stover. It is tolerant to drought and heat and also gives economical yield under stress conditions. Globally, pearl millet is cultivated on $\sim 30$ million ha hectares (Yadav et al., 2012). It is mostly cultivated in Asia ( 10 million ha) and Sub-Saharan Africa ( 18 million ha) for grain and stover purpose predominantly on marginal soils with low productivity. India is the leading producer of pearl millet with an area of $\sim 8.5$ million ha and a production of $\sim 9.0$ million ton during 2009 - 2013 (Jukanti et al., 2016). Pearl millet is largely cultivated as a rainy season crop in the arid and semi-arid regions of Asia and Africa. But, during the past decade with the availability of assured irrigation, it is being cultivated as a summer crop in several parts of northern and north-western parts of India with higher yield and better grain quality (Reddy et al., 2013). Under assured irrigation and with good management practices the grain and fodder yield of summer pearl millet are $\sim 4-5 \mathrm{t} \mathrm{ha}^{-1}$ and 8-10 $\mathrm{t} \mathrm{ha}^{-1}$, respectively (Gupta et al., 2015). The two major environmental constraints of pearl millet growing regions are heat stress and recurrence of drought. In several summer pearl millet cultivating regions of India, temperature is usually very high and sometimes reaches up to $\sim 45^{\circ} \mathrm{C}$.

Temperature stress is an important factor limiting growth and development including morphological, physiological and biochemical changes (Bhattacharjee, 2009) in plants. Based on the changing climate scenario and increasing temperature, different prediction models have reported 7.0 - 8.5\% reduction in global millet yield by 2050 (Nelson et al., 2009). Summer cultivation of pearl millet is mostly effected due to high temperature $\left(>42^{\circ} \mathrm{C}\right)$ and Vapour presence deficit during flowering (Gupta et al., 2015) period. Presently limited cultivars (hybrids or populations) are available with higher yielding ability for summer cultivation. Simultaneously, the narrow genetic variability of available cultivars is at a risk of being exposed to serious diseases like downy mildew or blast. The limited or nonavailability of cultivars with higher yielding ability emphasises the importance of breeding for high temperature tolerance. Further, it is also important to evaluate and identify different sources of high temperature tolerance which would aid in developing high yielding and stress tolerant cultivars specifically suited for summer cultivation.

\section{Materials and Methods}

Fourteen pearl millet cultivars (4 each of populations and hybrids; 3 each of inbred restorers and male-sterile [MS] lines) were sown in RBD with three replications. The hybrid (except GHB 538 and ICMH 356), population, inbred restorers and MS lines used in the present study were developed under 'Pearl Millet Breeding Program' at ICAR - Central Arid Zone Research Institute (CAZRI), Jodhpur, India. Each cultivar was sown in single row of 2 $\mathrm{m}$ length (plot) and inter and intra row spacing was $60 \mathrm{~cm}$ and 20 $\mathrm{cm}$, respectively. The study was conducted under two different sowing dates during 2014 and 2015 in such a way that the flowering was not/minimally affected by high temperature stress (non-stress - NST) and the flowering largely coincided with high temperature $\left(\geq 42^{\circ} \mathrm{C}\right)$ impacting the seed set and grain yield (stress - ST). The maximum and minimum temperature, relative humidity and vapour pressure deficit (VPD) were recorded at the flowering stage during 2014 and 2015. All the genotypes included in study were exposed to high temperature $\left(\geq 42^{\circ} \mathrm{C}\right)$ during flowering under stress conditions. The temperature range under non stress conditions during 2014 and 2015 was 33.2 to $43.0^{\circ} \mathrm{C}$ and 33.5 to $40.9^{\circ} \mathrm{C}$. Similarly, under ST conditions it was 41.0 to $44.0^{\circ} \mathrm{C}$ and 38.2 to $44^{\circ} \mathrm{C}$ respectively. Further, the vapour pressure deficit during flowering under NST during 2014 and 2015 was 2.88 to $3.90 \mathrm{k} \mathrm{Pa}$ and 1.14 to $4.90 \mathrm{k} \mathrm{Pa}$ respectively. Similarly, under ST conditions it was 4.90 to $6.03 \mathrm{k} \mathrm{Pa}$ and 3.64 to $6.35 \mathrm{k}$ Pa respectively. The sowing under NST and ST conditions was taken up during $1^{\text {st }}$ and $3^{\text {rd }}$ week of March during both the years. Field screening was performed by adopting good agronomic practices. The crop was irrigated at regular intervals depending upon the necessity to avoid drought like conditions.

The data on plant height, ear head girth, ear head length, and seed set per cent was recorded on five randomly selected plants. Days to $50 \%$ flowering was recorded when $50 \%$ stigmas had emerged i.e., 5-7 days after panicle emergence. Selected panicles were tagged to record the seed set following the standard ergot scale (Thakur and King, 1988), wherein the seed set was considered proportional to the ergot infected seeds. Days to $50 \%$ anthesis was recorded when $50 \%$ of the plants had shed their pollen grains. Grain yield of each cultivar was recorded on per plot basis. Based on the data recorded under NST and ST conditions, the change in ear head length, seed set percent and percentage reduction in grain yield was calculated. Further, the geometric mean (GM), heat susceptibility index (HSI) and heat tolerance index $(\mathrm{HTI})$ was calculated as per Fisher and Maurer (1978). The analysis of variance (ANOVA) was performed using SAS Version 9.3. Interrelationship among different traits were calculated using Pearson's correlation analysis (Fisher, 1924). The path coefficient analysis was performed according to Dewey and Lu (1959) to record direct and indirect effects of different traits on grain yield. The meteorological data was obtained from the meteorological unit of Central Arid Zone Research Institute, Jodhpur, India.

\section{Results and Discussion}

Wide variability and significant differences were observed for different characters among the fourteen pearl millet genotypes including four each of population/hybrids and three each of inbred restorers/MS lines evaluated for high temperature tolerance (Table 1). Plant height was consistently higher under ST conditions ( 98.7 to $185.8 \mathrm{~cm}$ ) compared to NST (86.3 to $155.0 \mathrm{~cm}$; Table 1) among all the genotypes. The populations were comparatively taller than other genotypes. The average increase 


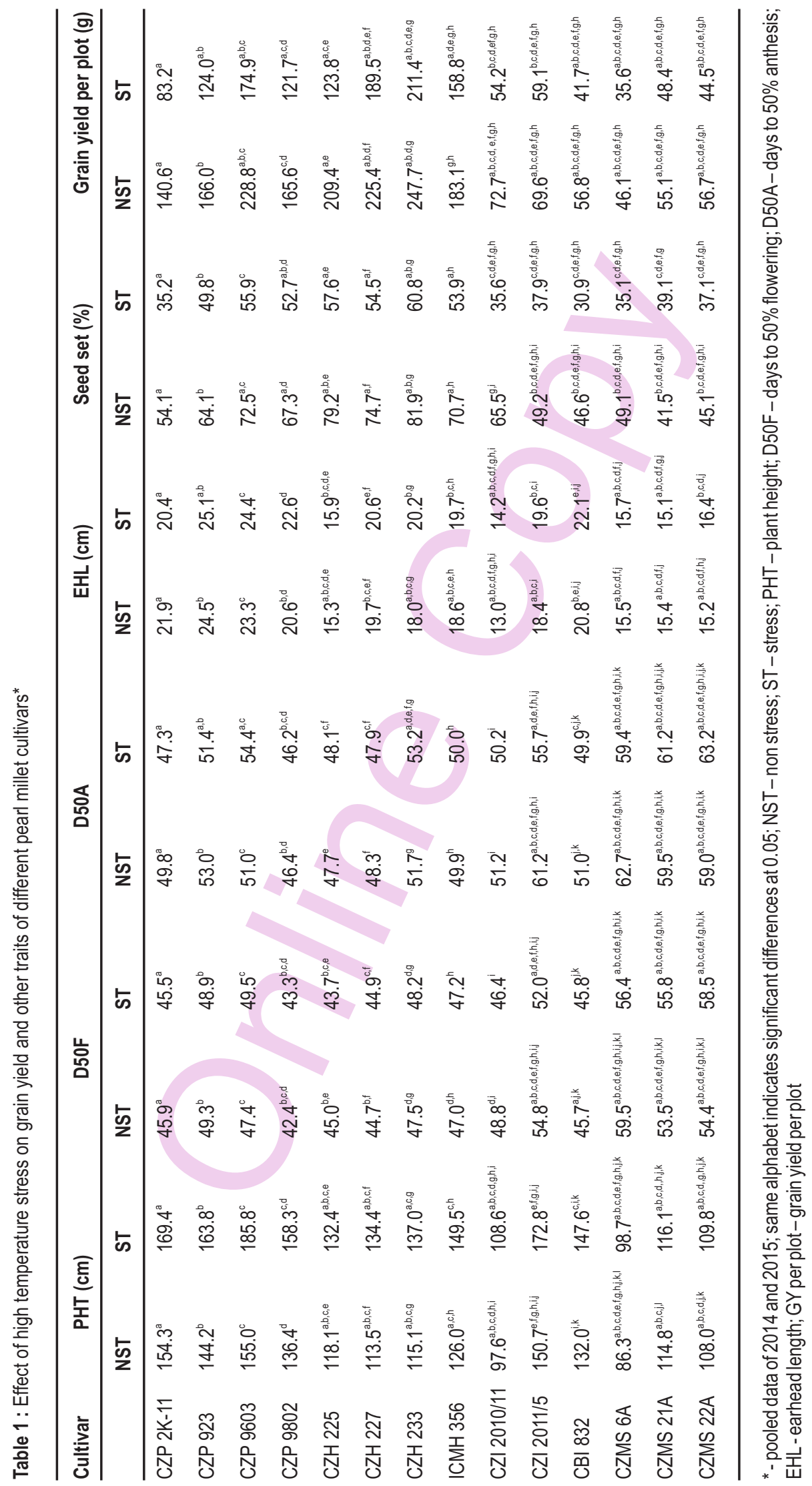


in plant height was: populations/hybrids $(\sim 21.0 \mathrm{~cm})$, inbred restorers $(\sim 16.0 \mathrm{~cm})$ and MS lines $(\sim 5.0 \mathrm{~cm}$; Table 1). The increase in plant height probably indicates that high temperature stress limits assimilate production/partitioning and reduced reproductive growth but enhanced vegetative growth (Suwa et al., 2010; Rattalino Edreira and Otegui, 2012). Yadav et al., (2014) also reported increase in plant height in pearl millet cultivars under heat stress compared to normal sowing conditions.

The range of days to $50 \%$ flowering under NST and ST was 42.4 to 59.5 days and 43.3 to 58.5 days. Similarly, days to $50 \%$ anthesis under NST and ST varied from 46.4 to 62.7 days and 46.2 to 63.2 days, respectively. The days to $50 \%$ flowering and anthesis did not show any consistency in their behaviour under ST compared to NST, except that high yielding genotypes took relatively more days for flowering ( 0.7 to 2.3 days) and anthesis ( 1.5 to 3.4 days) compared to others (Table 1 ). The delay in days to $50 \%$ flowering and anthesis under stress conditions indicates that pearl millet may have a possible mechanism to overcome heat stress. Although delayed flowering and anthesis is not reported in pearl millet under ST conditions, but Rattalino Edreira et al., (2011) reported delayed flowering time in maize under heat stress. Further, despite small increments in days to $50 \%$ flowering and anthesis, the spread of days to $50 \%$ flowering and anthesis period among the different genotypes reduced under ST (D50F - 2.7 to 6.2 days; D50A - 3.8 to 8.2 days) compared to NST ( 2.8 to 9.1 days; 3.7 to 10.2 days). Interestingly, reduction in flowering period in pearl millet, as a possible mechanism to overcome heat stress, has been observed under field conditions.

Ear head length increased under ST conditions among majority of the genotypes and range of increment was 0.3 to 2.2 $\mathrm{cm}$ (Table 1). The population exhibited longest ear heads (NST 20.6 to $24.5 \mathrm{~cm}$; ST -20.4 to $25.1 \mathrm{~cm}$ ) and MS lines the shortest $(15.2$ to $15.5 \mathrm{~cm} ; 15.1$ to $16.4 \mathrm{~cm})$ under both ST and NST environments (Table 1). A small increase in ear head length under high temperature stress was observed in contrast to a reduced ear head length as reported by Gupta et al., (2015). Increase in ear head length could probably result in better yield (specifically in tolerant genotypes) under stress condition via., relatively higher seed set per cent as exhibited by better yielding genotypes like CZP 9603 and CZH 233 under present study. This probably means that high temperature conditions had limited impact on different physiological processes including flowering dynamics, and biomass partitioning on reproductive organs at least in better performing genotypes. These processes when affected under stress conditions significantly increase the per cent floral abortion and reduce ear head growth leading to reduction in seed number i.e. seed set and grain yield (Cicchino et al., 2010).

Seed set per cent showed wide variability among different genotypes (Table 1). Hybrid, CZH 233 had highest seed set of $81.9 \%$ and $60.8 \%$ in NST and ST; whereas population CZP 9603 had highest seed set of $72.5 \%$ and $55.9 \%$. A reduction in seed set

Table 3 : Pooled geometric mean heat susceptibility index and heat tolerance index of pearl millet cultivars under high temperature stress

\begin{tabular}{|c|c|c|c|c|c|c|}
\hline $\begin{array}{l}\text { Cultivar } \\
\text { populations }\end{array}$ & $\begin{array}{l}\text { Yield-NST } \\
\text { (g per plot) }\end{array}$ & $\begin{array}{l}\text { Yield-ST } \\
\text { (g per plot) }\end{array}$ & GM & HSI & HTI & Rank \\
\hline CZP 2K-11 & 140.55 & 83.15 & 108.11 & 1.48 & 0.38 & 4 \\
\hline CZP 923 & 166.00 & 128.00 & 145.77 & 0.83 & 0.69 & 2 \\
\hline CZP 9603 & 228.80 & 174.85 & 200.01 & 0.86 & 1.30 & 1 \\
\hline CZP 9802 & 165.60 & 121.70 & 141.96 & 0.96 & 0.66 & 3 \\
\hline \multicolumn{7}{|l|}{ Hybrids } \\
\hline CZH 225 & 209.35 & 123.80 & 160.99 & 1.94 & 0.55 & 4 \\
\hline CZH 227 & 225.35 & 189.45 & 206.62 & 0.76 & 0.91 & 2 \\
\hline CZH 233 & 247.70 & 211.40 & 228.83 & 0.70 & 1.12 & 1 \\
\hline ICMH 356 & 183.05 & 158.75 & 170.47 & 0.63 & 0.62 & 3 \\
\hline \multicolumn{7}{|l|}{ Inbred Restorers } \\
\hline CZI 2010/11 & 72.65 & 54.15 & 62.72 & 1.15 & 0.89 & 2 \\
\hline CZI 2011/5 & 69.55 & 59.05 & 64.09 & 0.68 & 0.93 & 1 \\
\hline CBI 832 & 56.80 & 41.65 & 48.64 & 1.20 & 0.54 & 3 \\
\hline \multicolumn{7}{|l|}{ MS lines } \\
\hline CZMS 6 & 46.05 & 35.55 & 40.46 & 1.00 & 0.77 & 3 \\
\hline CZMS 21 & 55.10 & 48.40 & 51.64 & 0.65 & 0.96 & 1 \\
\hline CZMS 22 & 56.70 & 44.50 & 50.23 & 1.16 & 0.91 & 2 \\
\hline
\end{tabular}

$\mathrm{GM}=((\mathrm{Ys} X \mathrm{Yp}) 1 / 2) ; \mathrm{HSI}=\left(1-\left(Y_{s}-Y_{p}\right)\right) /(1-(X s-X p)) ; H T I=(Y p X Y s) / X p 2$, where $Y s$ and $Y p$ are genotypic yield under stress and non-stress conditions respectively, and $X s$ and $X p$ are the mean yield of all genotypes under stress and non-stress conditions 
Table 2 : Percentage decrease in seed set and grain yield (GY)/plot under ST conditions as compared to NST conditions

\begin{tabular}{llll}
\hline Cultivar & $\begin{array}{l}\text { Change in } \\
\text { EHL }(\mathbf{c m})\end{array}$ & $\begin{array}{l}\text { Decrease in } \\
\text { seed set }(\%)\end{array}$ & $\begin{array}{l}\text { Decrease in } \\
\text { grain yield/plot } \\
(\%) 18\end{array}$ \\
\hline CZP 2K-11 & -1.6 & 18.9 & 35.5 \\
CZP 923 & 0.7 & 14.3 & 25.3 \\
CZP 9603 & 1.1 & 16.7 & 23.4 \\
CZP 9802 & 2.1 & 14.6 & 26.5 \\
CZH 225 & 0.7 & 21.7 & 40.9 \\
CZH 227 & 1.0 & 20.2 & 16.3 \\
CZH 233 & 2.2 & 21.1 & 14.5 \\
ICMH 356 & 1.1 & 16.8 & 13.2 \\
CZI 2010/11 & 1.2 & 29.9 & 25.6 \\
CZI 2011/5 & 1.2 & 11.3 & 15.8 \\
CBI 832 & 1.6 & 15.7 & 26.6 \\
CZMS 6 & 0.3 & 14.0 & 22.7 \\
CZMS 21 & -0.3 & 2.4 & 12.2 \\
CZMS 22 & 1.2 & 12.2 & 21.5 \\
\hline
\end{tabular}

$\mathrm{EHL}$ - earhead length

per cent among the tested genotypes under ST varied from 2.4 to $29.9 \%$ (Table 2). The average reduction in seed set per cent was $\sim 20 \%$ among hybrids and inbred restorers, $\sim 17.4 \%$ in population and $\sim 10.0 \%$ in 'MS' lines (Fig. 1). It was also noticed that high yielding genotypes had recorded lower reduction in seed set per cent (Table 1). There are limited studies on pearl millet showing the effect of high temperature on different traits including seed set per cent at flowering. Gupta et al. (2015) reported reduced seed set per cent under high temperature at flowering in pearl millet. Differential response to high temperature stress at flowering has been studied in cereals including maize (Edriera et al., 2011), wheat (Talukder et al., 2014) and rice (Prasad et al., 2006).

Grain yield per plot was higher among the populations/hybrids compared to inbred restorers/MS lines. A wide variability was observed among the different genotypes for grain yield (NST - 46.1 to $247.7 \mathrm{~g} / \mathrm{plot}$; ST - 35.6 to $211.4 \mathrm{~g} / \mathrm{plot}$ ). CZH 233 (NST - $247.7 \mathrm{~g} / \mathrm{plot}$; ST - $211.4 \mathrm{~g} / \mathrm{plot}$ ) and CZP 9603 (228.8 g/plot; $174.9 \mathrm{~g} / \mathrm{plot}$ ) were the highest performers under both the conditions. The per cent reduction in grain yield was observed to range from 12.2 to 40.9 (Table 2). Overall, the population recorded highest reduction in grain yield per plot $(27.2 \%)$ followed by inbred restorers ( 22.7\%), hybrids (21.2\%) and MS lines (18.8\%) (Fig. 1). Among the hybrids/populations, ICMH 356 (13.2\%) and CZP 9603 (23.4\%) showed lowest reduction in grain yield, but overall the lowest reduction of grain yield was observed in CZMS 21. The average grain yield per plot under ST conditions of different genotypes is as follows : hybrids $170.9 \mathrm{gm}$, population - $126.9 \mathrm{gm}$, inbred restorers - $51.7 \mathrm{gm}$ and MS lines - $42.8 \mathrm{gm}$. Though a significant positive correlation of grain yield with seed set was expected; a significant positive

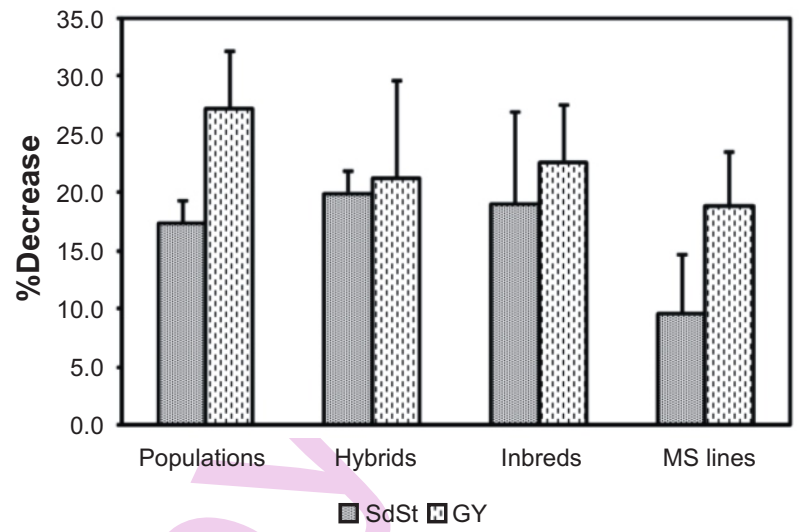

Fig. 1 : Average per cent decrease of grain yield and seed set in different types of pearl millet cultivars during 2014 and 2015

correlation with ear head length was interesting, especially under ST conditions. Further, grain yield per plot and seed set per cent under ST conditions showed negative correlation with flowering as reported in wheat under similar conditions (Gupta et al., 2007).

Geometric mean, heat susceptibility index and heat tolerance index of different genotypes was estimated based on the grain yield per plot under NST and ST (Table 3). CZH 233 (228.83 g/plot) and CZP 9603 (174.85 g/plot) recorded highest GM among hybrids and population, respectively. The heat susceptibility index and heat tolerance index exhibited a wide variation of 0.63 (ICMH 356) to 1.94 (CZH 225) and 0.38 (CZP 2K11) to 1.30 (CZP 9603), respectively (Table 3). The highest average heat tolerance index of 1.10 was observed among the hybrids. The better performing genotypes had lower heat susceptibility index and higher heat tolerance index scores viz., CZP 9603 - 0.86/1.30; CZH 233 - 0.70/1.12; CZI 2011/5 0.68/0.93; and CZMS 210.65/0.96 (Table 3).

Correlations among different characters were estimated independently for two different environments (data not shown). Similar trends under both NST and ST conditions were observed. Grain yield per plot had a high significant positive correlation with ear head length (NST - 0.439; ST - 0.509) and seed set per cent (0.896; 0.864); whereas seed set per cent had a positive relation with ear head length $(0.194 ; 0.348)$. Seed set per cent exhibited a significant negative correlation with days to $50 \%$ flowering and anthesis and it had direct positive effect on grain yield under both NST and ST (Table 4). Further, ear head length exhibited a highly significant and positive correlation with plant height $(0.809$; 0.827 ); days to $50 \%$ flowering showed highly significant but negative relation with seed set per cent $(-0.681 ;-0.472)$ and grain yield per plot $(-0.664 ;-0.490)$. Days to $50 \%$ flowering, seed set per cent and ear head length had a strong direct positive effect on grain yield per plot; plant height and days to $50 \%$ flowering had a direct negative effect (Table 4). Plant height exhibited a positive 


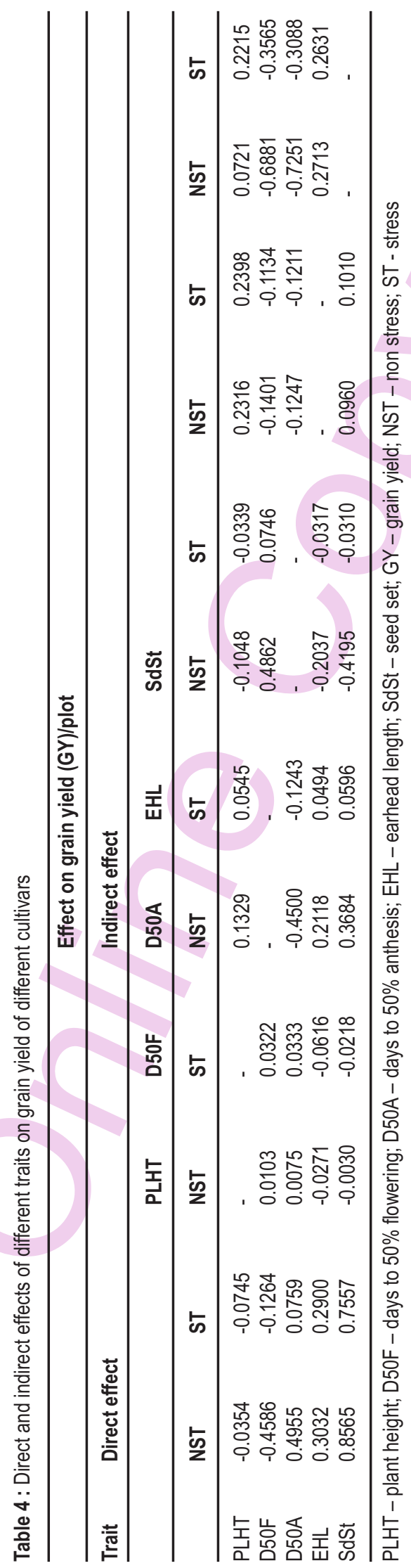


indirect effect through days to $50 \%$ flowering, ear head length and seed set per cent. Days to $50 \%$ flowering and anthesis had positive indirect effect through plant height, but a negative indirect impact through ear head length and seed set per cent. The seed set per cent had indirect but positive impact through days to $50 \%$ flowering and ear head length. Similarly, positive indirect effect of ear head length was observed through days to $50 \%$ flowering and seed set per cent.

Overall, on the basis of average seed set per cent, reduction in seed set and grain yield it can be concluded that hybrids performed relatively better than population. Though hybrids are the most suited type of cultivars, considering the increasing cost of hybrid seed production some high yielding population (like CZP 9603) that are suitable for local conditions could provide the farmers with a sustainable alternative, specifically in the arid regions.

\section{Acknowledgments}

The authors acknowledge the Director, ICAR-Central Arid Zone Research Institute (CAZRI), Jodhpur, India for supporting this study. The authors would also like to thank Mr. Manohar Singh Solanki, Technical Officer, ICAR-CAZRI, Jodhpur and Mr. Prakash Kalwani, SRF, ICAR-CAZRI, Jodhpur, for their help during field operations and data recording.

\section{References}

Bhattacharjee, S.: Involvement of calcium and calmodulin in oxidative and temperature stress of Amaranthus lividus L. during early germination. J. Environ. Biol., 30, 557-562 (2009).

Cicchino, M., J. I. Rattalino, M. Uribelarrea and M. E. Otegui: Heat stress in field-grown maize: Response of physiological determinants of grain yield. Crop Sci., 50, 1438-1448 (2010).

Deway, D. R. and K. H. Lu: A correlation and path coefficient analysis of components of crested wheat grass seed production. Agron. J., 51,515-518(1959).

Fisher, R. A. and R. Maurer: Drought resistance in spring wheat cultivars. I. Grain yield responses. Aust. J. Agric. Res., 29, 897912 (1978).

Gupta, S. K., K. N. Rai, P. Singh, V. L. Ameta, S. K. Gupta, A. K. Jayalekha, R. S. Mahala, S. Pareek, M. L. Swami and Y. S. Verma: Seed set variability under high temperatures during flowering period in pearl millet (Pennisetum glaucum L. (R.) Br.). Field Crops Res., 171, 41-53(2015).

Gupta, D., R.K. Mittal, A. Kant and M. Singh: Association studies for agrophysiological and quality traits of triticale $\mathrm{X}$ bread wheat derivatives in relation to drought and cold stress. J. Env. Biol., 28, 265-269 (2007).

Jukanti, A.K., C.L.L Gowda, K.N. Rai, V.K. Manga and R.K. Bhatt: Crops that feed the world 11. Pearl millet (Pennisetum glaucum L.): an important source of food security, nutrition and health in the arid and semi-arid tropics. Food Sec., 8, 307-329 (2016).

Nelson, G.C., M. W. Rosegrant, J. Koo, R. Robertson, T. Sulser, T. Zhu, C. Ringler, S. Msangi, A. Palazzo, M. Batka, M. Magalhaes, M. Valmonte-Santos, M. Ewing and D. Lee: Climate change impact on agriculture and costs of adaptation. In: Food Policy Report, International Food Policy Research Institute (IFPRI), Washington D.C, USA, p. 19 (2009).

Prasad, P. V. V., K. J. Boote, L. H. Allen, J. E. Sheehy and J. M. G. Thomas: Species, eco-type and cultivar differences in spikelet fertility and harvest index of rice in response to high temperature stress. Field Crops Res., 95, 398-411 (2006).

Rattalino Edreira, J. I. and M. E. Otegui: Heat stress in temperate and tropical maize hybrids: differences in crop growth, biomass partitioning and reserves use. Field Crops Res., 130, 87-98 (2012).

Rattalino Edreira, J. I., E. B. Carpici, D. Sammarro and M. E. Otegui: Heat stress effects around flowering on kernel set of temperate and tropical maize hybrids. Field Crops Res., 123, 62-73 (2011).

Reddy, A. R., P. Parthasarathy Rao, O. P. Yadav, I. P. Singh, N. J. Ardeshna, K. K. Kundu, S. K. Gupta, R. Sharma, G. Sawargaonkar, D. P. Malik, D. Shyam Moses and S. K. Reddy: Prospects for kharif (rainy season) and summer pearl millet in Western India. Working Paper Series No. 36. International Crops Research Institute for the Semi-Arid Tropics, Patancheru, Andhra Pradesh, India, p. 24 (2013).

Suwa, R. H., H. H. Hakata, H. A. El-Shemy, J. J. Adu-Gyamfi, N. T. Nguyen, S. Kanai, D. A. Lightfoot, P. K. Mohapatra and K. Fujita: High temperature effects on photosynthate partitioning and sugar metabolism during ear expansion in maize (Zea mays L.) genotypes. Plant Physiol. Biochem., 48, 124-130 (2010).

Talukder, A. S. M. H. M., G. K. McDonald and G. S. Gill: Effect of shortterm heat stress prior to flowering and early grain set on the grain yield of wheat. Field Crops Res., 160, 54-63 (2014).

Thakur, R. P. and S. B. King: Ergot disease of pearl millet. In: Information Bulletin No.24. International Crops Research Institute for the Semi-Arid Tropics, Patancheru, Andhra Pradesh, India, p. 24 (1988).

Yadav, O.P., K. N. Rai, B. S. Rajpurohit, C. T. Hash, R. S. Mahala, S. K. Gupta, H. S. Shetty, H. R. Bishnoi, M. S. Rathore, A. Kumar, S. Sehgal and K. L. Raghvani: Twenty-five years of pearl millet improvement in India. All India Coordinated Pearl Millet Improvement Project (AICPMIP), Jodhpur, India (2012).

Yadav, A.K., R. K. Arya and M. S. Narwal: Screening of pearl millet F1 hybrids for heat tolerance at early seedling stage. Adv. Agric., 2014, 1-17 (2014). 